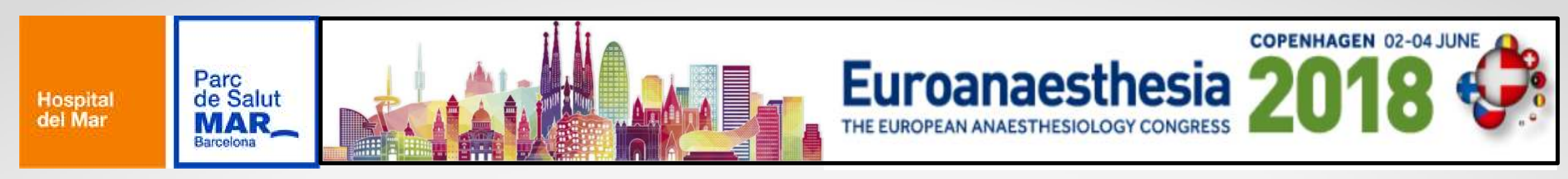

\title{
Retrospective cohort study of postoperative pneumonia comparing volatile versus total intravenous anaesthesia in thoracic surgery
}

A. Pardo Bedia, A. Benitez-Cano, A. Rodriguez Fuster, R. Aguiló Espases, E. Samsó Sabe, S. Bermejo Martinez. Parc de Salut Mar. Institut Hospital del Mar d'Investigacions Mèdiques (IMIM), Universitat Autònoma de Barcelona.

\section{Background and Goal of Study}

Postoperative pneumonia after thoracotomy for pulmonary resection has been associated to the type of general anaesthetic received ${ }^{1-3}$, but reports about this topic showed contradictory results. The goal of this study was to compare the incidence of postoperative pneumonia (including tracheobronquitis ${ }^{4}$ ) after thoracic surgery when volatile or total intravenous anaesthesia was administered.

\section{Materials and Methods}

\section{Retrospective cohort study}

Hypnotic administered:

- Sevoflurane $(n=78)$

- Propofol $\quad(n=151)$

Jan 2011

May 2017

(229 elective thoracotomies)

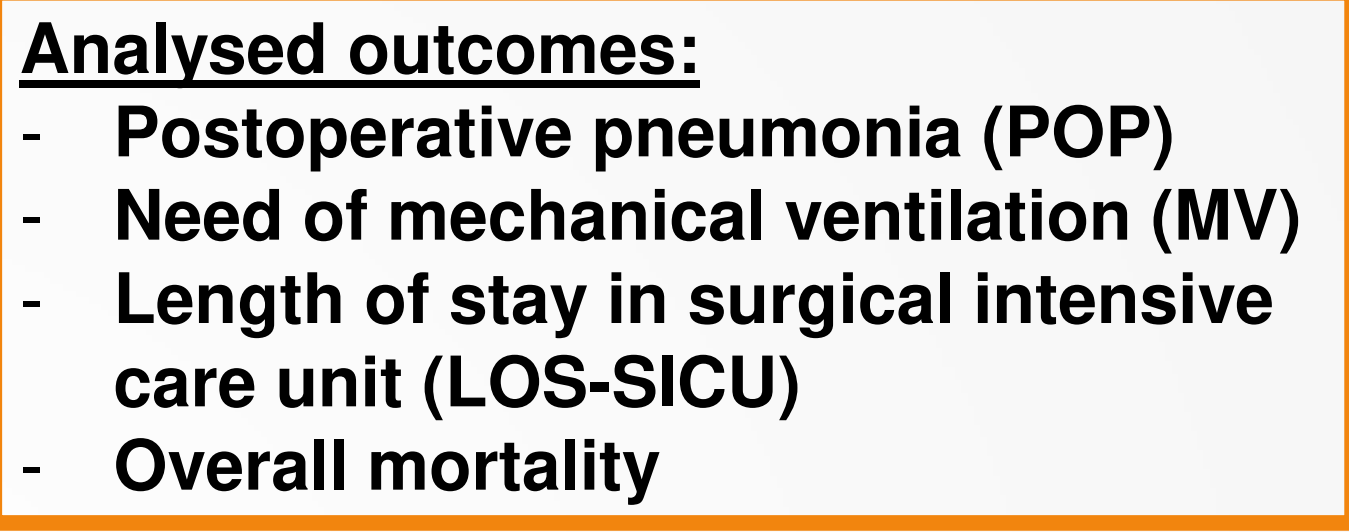

Analysed outcomes:

Postoperative pneumonia (POP) Need of mechanical ventilation (MV) Length of stay in surgical intensive care unit (LOS-SICU)

Overall mortality

Statistics: Chi2 and Mann-Whitney tests were used to analyse dependent variables by type of hypnotic. Multivariate analysis was performed adjusting by potential confounders.

\section{Results and Discussion}

Patient characteristics were similar between both groups (Table). Results of the study are included in the graphic. POP was similar between the groups. MV and overall mortality trend to be higher in sevoflurane group but no differences were detected. LOS-SICU trend to be also higher in sevoflurane group (4.0 \pm 11.8 vs $5.1 \pm 8.9$ days, HR $0.85[95 \% \mathrm{Cl}, 0.63-1.13])$.

\begin{tabular}{|l|c|c|}
\hline & $\begin{array}{c}\text { Sevoflurane } \\
(\mathrm{n}=78)\end{array}$ & $\begin{array}{c}\text { Propofol } \\
(\mathrm{n}=151)\end{array}$ \\
\hline Age (years) & $64 \pm 10$ & $64 \pm 10$ \\
\hline $\begin{array}{l}\text { Gender } \\
\text { men/women (\%) }\end{array}$ & $72 / 28$ & $72 / 28$ \\
\hline FEV1 (\%) & $73 \pm 20$ & $69 \pm 20$ \\
\hline $\begin{array}{l}\text { ASA status } \\
(2 / 3 / 4)(\%)\end{array}$ & $31 / 67 / 3$ & $34 / 60 / 5$ \\
\hline ARISCAT1 score $^{\text {(2) }}$ & $27 \pm 19$ & $25 \pm 19$ \\
\hline RFMDR $^{2}$ (\%) & 42 & 40 \\
\hline
\end{tabular}

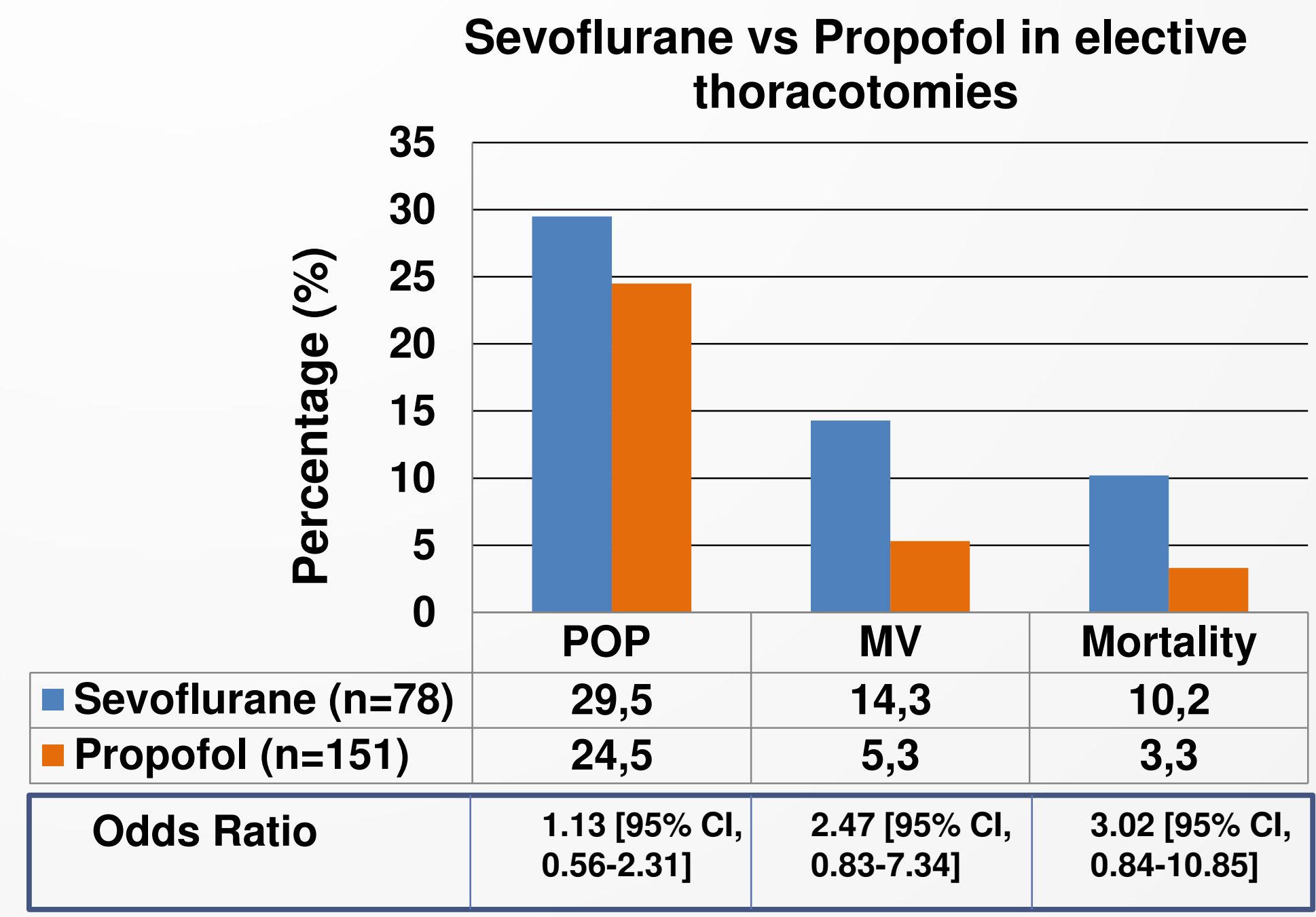

Table. ${ }^{1} \boldsymbol{A R I S C A T :}$ Assess Respiratory Risk in Surgical
Patients in Catalonia risk index. ${ }^{2}$ RFMDR: Risk factors for Multi-Drug Resistant Pathogens.

Graphic. Results of the analysed outcomes considering the administered hypnotic.

\section{Conclusion}

The incidence of postoperative pneumonia after thoracic surgery was similar between patients regardless of the hypnotic administered. We observed an association between sevoflurane and higher mechanical ventilaton, length of stay in surgical intensive care unit and overall mortality. However, not statistical significance were found. Further prospective research is needed to confirm these results.

\section{References}

